\title{
MORRE O BOI: \\ VESTÍGIOS DO TRÁGICO EM DRUMMOND DE BOITEMPO
}

\author{
Fernanda Ferrari Zrzebiela*
}

RESUMO: Propõe-se a leitura de dois poemas de Carlos Drummond de Andrade: "Destruição" e "O belo boi de Cantagalo", inseridos na trilogia Boitempo, a partir da evocação do boi e de sua relação com a morte. Quer-se pensar aqui o motivo bovino não apenas enquanto modo de referência mais direta à economia do clã dos Andrade, mas também - e principalmente - em seu aspecto potencialmente trágico, tanto como forma pronta à degradação, quanto promessa de sobrevivência que se afirma pela transformação ou alteração dos estados.

PALAVRAS-CHAVE:

Carlos Drummond de Andrade; Memória; Poesia.

“O mais trágico dos nossos poetas"

Apesar de pouco estudado, o aspecto trágico da poesia de Drummond fora percebido inicialmente por Mário de Andrade que em carta do dia 15 de outubro de 1944, por ocasião do então recém-lançado Confissões de Minas, comenta:

Se eu disse no princípio que li as Confissões achando você em cada frase mas não me achando, é só por essa diferença nossa: a sua dramática capacidade de ser si mesmo e consequente solidão trágica (no

\footnotetext{
* Doutoranda em Literatura pela Universidade Federal de Santa Catarina (Ufsc), bolsista CNPq. Mestre pela mesma instituição. Licenciada em Letras Português/Inglês e respectivas literaturas pela Universidade Estadual de Ponta Grossa (UEPG). Integrante do Núcleo de Estudos Literários \& Culturais (Nelic-Ufsc).
} 
meu sentido de trágico, isto é, a fatalidade duma predestinação invencível) [...] (ANDRADE; ANDRADE, 2002, p. 532).

Isso porque, como explica o autor de Macunaíma no início da mesma carta, ao ler Confissões encontra sempre Drummond, mas não acha “a si mesmo”, já que sua "angustiosa impossibilidade de solidão" ("E não será isso que faz de mim um infatigável escrevedor de cartas?...”) o impede de "exercer" aquela solidão trágica que seria justamente "uma das diferenças mais essenciais e características" da personalidade poética drummondiana ${ }^{1}$.

Ao que parece, Mário intencionava realizar um estudo sobre a poesia drummondiana no qual certamente abordaria este aspecto em relação ao qual tanto insistira na carta ${ }^{2}$. Apesar de não tê-lo conceituado na ocasião, pouco antes, em um ensaio dedicado às Três Tragédias à Sombra da Cruz, de Otávio de Faria, Mário definia "trágico" numa perspectiva semelhante àquela comentada na carta a Drummond, ou seja, como o resultado de uma "antinomia entre o limitado humano e o ilimitado da fatalidade" (ANDRADE, 1972, p. 111).

A herança trágica na lírica de Drummond, nesses termos, diria respeito a um senso de fatalidade ou de destino, resultante da tensão entre a anánkè, imposta de fora, e a decisão pessoal no agir: conflito entre indivíduo e ordem na qual se insere, de que são prova os versos de "Os bens e o sangue", por exemplo ${ }^{3}$. De modo que a hipertrofia da individualidade, na poesia drummondiana nasce como um problema que impinge ao sujeito a vivência

\footnotetext{
1 "Mas eu creio que o caráter trágico da sua poesia, revertido à substância da sua solidão ('essa cabeça baixa', o assustador diálogo de você com a menina no bonde etc.) é uma pista boa pra denunciar uma das diferenças mais essenciais e características da sua personalidade poética, não acha não? Se não achar, me avise, por favor, pra eu não errar demais" (ANDRADE; ANDRADE, 2002, p. 534).

2 "Estou decidido a escrever o ano que vem um estudo sobre você. Enfim agora vai mesmo. O ano que vem vou me enterrar em poesia e, garantidos, sairão dois ensaios sobre você e o Manuel. E provavelmente outro sobre o Murilo Mendes" (ANDRADE; ANDRADE, 2002, p. 533). Mário morreria no início do ano seguinte.

${ }^{3}$ Destinado pelos antepassados, divinizados no poema, a obter sustento de algum "mel nojento", o poeta não pode escolher ser quem é, já que, "condenado", é incapaz de escolher. Se se julga livre para fugir, na tentativa de se desvencilhar e fundar nova origem, é somente para reconhecer (-se), depois da busca/fuga a que se lança, exatamente o contrário do que acreditava e parecia ser. Marlene de Castro Correia, quando analisa o poema em questão, esclarece que a liberdade do sujeito se restringe em assumir a condição de objeto de uma escolha: a de cumprir a missão que lhe fora predestinada pelos antepassados, qual seja redimi-los da decadência e da morte, promover a comunhão e assegurar a perenidade do grupo familiar pela poesia (2002, p. 92-93).
} 
da experiência poética frequentemente associada ao sentimento de culpa, concorrendo, para tanto, imagens de expiação e automutilação, além da proximidade com o sujo e o impuro, conforme já esquadrinhado por Antonio Candido 4 .

\section{O tempo da dissolução}

Vagner Camilo (2001), quando analisa poemas que tratam do passado familiar, em Claro enigma, propõe que o sentimento de culpa neles expresso se estende não só à relação social, mas atinge também a própria concepção de História. Sem qualquer perspectiva de redenção, a obediência à lei natural da transitoriedade e da perecibilidade assume, assim, um caráter de sujeição do existente a um destino irrevogável: "o pó viestes e ao pó retornarás". Se esse movimento de queda segue o seu contrário, em que as pedras vão "severas se erguendo" pela construção humana, o ciclo se perfaz: das ruínas que se refazem em arquitetura, de novo se encena, pelo mesmo movimento, a repetição da catástrofe. A essa concepção de história naturalizada corresponde a ideia de tempo pautado pelo eterno retorno, cuja expressão máxima talvez esteja nos "mesmos sem roteiros tristes périplos" a que aludem os famosos versos de "A máquina do mundo".

Também em Boitempo ${ }^{5}$, ao contrário do que estabelece a crítica ${ }^{6}$, o poeta não deixará

\footnotetext{
${ }^{4}$ No poema "A Mão suja”, por exemplo, de José, a “mão incurável que polui o ser, impede o contato com o semelhante e cria a ânsia de purificação". A mão é insígnia ignóbil, "mão de um sujo vil", como uma marca de nascença que o lembrasse a todo instante da distância que separa ele, sujeito "sujo pardo,/ pardo, tardo, cardo", daquele sujo "preto tão puro", "de terra, de carvão", de "suor na camisa de quem trabalhou"(1970, p. 72-73).

${ }^{5}$ Ao contrário da larga tradição de escritores que comumente escolhe a prosa como palco de suas memórias, Drummond inicia em 1968 a publicação do primeiro volume das suas memórias em verso sob o título de Boitempo que, na ocasião, sai em conjunto com o livro $A$ falta que ama, pela editora Sabiá. O volume seguinte, Boitempo II Menino antigo, é publicado em 1973, pela Sabiá-José Olympio e o último deles, Boitempo III - Esquecer para lembrar, pela José Olympio, em 1979. Boitempo I e III são segmentados em nove partes (Boitempo I: "Caminhar de costas"; "Vida paroquial”; "Morar"; "Bota e espora"; "Notícias do clã"; "Um"; "Percepções"; "Relações humanas"; "Outras serras". Boitempo III: "Bens de raiz"; "Fazenda dos Doze Vinténs ou do Pontal"; "Terras em redor", "Morar nesta casa", "Notícias do Clã", "O menino e os Grandes", "Repertório urbano", "Primeiro colégio", "Fria Friburgo", "Mocidade solta") o que torna praticamente inevitável a comparação com as nove partes de Lição de coisas e as também nove da Antologia poética, ambas de 1962, enquanto que o segundo é dividido em quatro: "Pretérito mais-que-perfeito"; "Fazenda dos doze vinténs ou do Pontal"; "Repertório urbano"; "O Pequeno e os Grandes".
}

${ }^{6}$ A propósito de Boitempo, Antonio Candido notou que o "intuito autobiográfico não ocorre sob o aspecto de autoanálise, dúvida, inquietude, sentimento de culpa, ou seja, as vestimentas com que aparece na maioria da lírica 
de incorporar à atividade poética a experiência do trágico, que parece se dar, dentre outras formas, pelo sentimento de dissolução.

Em “Casarão Morto”, de Boitempo II (ANDRADE, 1973, p. 28), a presença humana é substituída pelos restos produzidos pela História: “esqueletos de cadeiras sem palhinha”, "retratos a óleo de feios latifundiários” que vão sendo substituídos por “cabrestos, loros, barbicachos". Se os retratos do século XIX traduzem certa "ambição de eternidade", de que nos fala Benjamin (2012, p. 96), a situação dos retratos de família, descritos por Drummond, parece divergente: o sangue talvez se preserve, mas os bens esvaem-se. A ação do tempo sobre o papel fotográfico é apenas a manifestação física de uma metamorfose maior e mais lenta, já que se perderam no tempo os valores que os retratados mais prezavam: o dinheiro, as viagens, as memórias (TEIXEIRA, 2005, p. 145). A antiga presença se converte agora em espectro: são personagens extintos que emergem do retrato empoeirado; o que antes era "Casarão", agora é "Paiol, depósito de trastes não íntegros, "aleijados". Antiga glória fazendeira traduzida em derrota.

Ao longo dos três livros, confronta-se o leitor com uma série de poemas que ironizam a dissolução do clã ao longo do tempo, processo que atingirá desde os instrumentos de sua atividade econômica, como se pode ler em "Agritortura” (Boitempo III)7, até a queda da própria atividade econômica em si, da qual a lagartixa desponta como "herdeira única"

de Drummond; mas com aquele sentimento do mundo como espetáculo, que se configura nalguns poemas de Lição de coisas. A impressão é de que o poeta incluiu deliberadamente a si mesmo na trama do mundo como parte do espetáculo, vendo-se de fora para dentro. Dir-se-ia então que a tonalidade dos últimos livros é fruto de uma abdicação do individualismo extremado, em favor de uma objetividade que encara serenamente o eu como peça do mundo" (1989, p. 55). Também para José Guilherme Merquior, "uma vez confessados sentimentos muito tempo escondidos aos seus mortos mais caros e próximos" o poeta teria chegado, em Boitempo, a uma "serenidade benéfica", "espécie de beatitude sentimental": "O livro não é sequer catártico: sua inspiração geral é a paz, a serenidade de alma que sucede à catarse" (2012, p. 299). Na mesma esteira, Vagner Camilo entende que após a "enfática admissão de culpa ela parece se extinguir, respondendo pela relação menos conflituosa e mais distanciada com o passado familiar", que "praticamente deixa de ser tematizado" em A vida passada a limpo, para reaparecer depois, "noutro registro, liberto e gaio, em Lição de coisas e, mais ainda, nos livros memorialísticos da série Boitempo" (2001, p. 276).

7 “Amanhã serão graças/ de museu./ Hoje são instrumentos de lavoura,/ base veludosa do Império:/ "anjinho",/ gargalheira,/ vira-mundo./ Cana, café, boi/ emergem ovantes dos suplícios./ O ferro modela espigas/ maiores./ Brota das lágrimas e gritos/o abençoado feijão/ da mesa baronal comendadora" (ANDRADE, 1979, p. 5). 
(“O resto", Boitempo II) ${ }^{8}$. Do clã, "restou, talvez? este pigarro"

A potência destrutiva do tempo não se restringe, contudo, à esfera econômica em torno da qual se sustentava o sistema de poder que o clã representava, mas atinge tanto a perda de um mundo concreto de segurança, quanto a decadência de valores que outrora assinalavam o seu prestígio, caso de "A condenada" (Boitempo III) ${ }^{10}$, poema que encerra o drama dos "tristes tempos" em que moças "belas, brancas, ricas” são condenadas ao casamento consigo mesmas, já que não saltam nesta terra príncipes “do armorial para pedirlhes a mão".

Contudo, talvez seja justamente pela evocação da última atividade econômica do clã, desempenhada pelo coronel Carlos de Paula Andrade, que Boitempo evidencia poemas de carga emotiva mais expressiva. Refiro-me aqui, em especial, a dois deles: "Destruição", de Boitempo II (ANDRADE, 1973, p. 32), inserido na seção que recebe o nome de "Fazenda dos 12 Vinténs ou do Pontal"11 e "O belo boi de Cantagalo" (ANDRADE, 1979, p. 13),

8 "O resto/ No alto da cidade/ a boca da mina/ a boca desdentada da mina de ouro/ onde a lagartixa herdeira única/ de nossos maiores/ grava em risco rápido/ no frio, na erva seca, no cascalho/ o epítome-epílogo/ da Grandeza" (ANDRADE, 1973, p. 36).

9 "Herança", Boitempo I (ANDRADE, 1968, p. 63).

10 "Impossível, casar a moça/ bela branca rica/ na terra onde príncipes não saltam/ do armorial para pedir-lhe a mão/ jamais./ Passam cometas de olhar astuto,/ canastras sortidas./ Irão comprar a moça, mercadoria/ sem preço na Terra/ Jamais./ Passam fazendeiros, botas esculpidas/ no estrume, riso ruidoso/ de dentes de ouro./ Cuidam, levar a moça para saldar/ suas hipotecas?/ Jamais./ Passam mulatos de fina lábia/ e mil apólices federais./ Como deixar que o sangue cruze/ na alva barriga de alvas origens?/ Jamais./ Condena-se a moça ao casamento/ consigo mesma/ na noite alvíssima/ eternamente./ Agora desimpedidos, os membros do clã podem "escolher par a seu gosto" (ANDRADE, 1979, p. 30).

${ }^{11}$ Em 1926, já casado e dividido entre a ajuda financeira e a censura muda do pai, Drummond se muda para Itabira com o intuito de assumir a fazenda em questão, legada pela família ao poeta e ao seu irmão, Altivo. A vida no interior, contudo, não parece atrair o poeta nem lhe trazer boas recordações, conforme atesta a correspondência do escritor à época. Em carta para o amigo Capanema, Drummond usa do humor para expor sua inadaptação à cidade: "Te comunico meu novo endereço: Itabira do Mato Dentro, Minas. É um lugar muito feio onde dizem que dá muito dinheiro, mas acho que é mentira" (Carta de 1926, não datada. Documento sob a guarda do CPDOC/ FGV). Como atesta José Maria Cançado (2012, p. 119), Drummond "andava pouco agradecido à vida", principalmente pelo fato de ainda não ter ganho, por aquela época, nenhum dinheiro pelos próprios meios. A resistência de Drummond é estimulada, em grande medida, por Mário de Andrade que aconselha ao amigo não temer os efeitos da cidade pequena, aproveitando os benefícios decorrentes da vida ao ar livre. Em carta de 8 de junho de 1926, Mário escreve: "Conselho final: deixe de colecionar selos e colecione bichinhos esquisitos barbuletas besouros etc. É muito mais ar-livrista e higiênico" (ANDRADE; ANDRADE, 2002, p. 223-225). As orientações de Mário parecem ajudar o poeta, de início, a olhar a cidade com um pouco mais de ternura: "Itabira é coisa deliciosa, gostosa na boca... [...] Outro dia levei um tombo do cavalo em frente à casa dum irmão meu, além 
de Boitempo III.

Enquanto motivo específico, a figura do boi é anterior aos textos literários, traduzindo-se numa espécie de imagem cifrada, corrente e enigmática: mitificado em várias culturas e civilizações, o boi era popularmente representado como um animal sagrado, no antigo Egito; guardião do Labirinto, em Creta; imolado em rituais religiosos, entre os gregos e representado pela primeira letra (Alef), no alfabeto hebraico. No complexo, variado e ambivalente simbolismo a que a sua figura está associada, a imagem do boi pode evocar, ainda, o espírito macho combativo, força fertilizante, que tanto pode se referir à sexualidade quanto à perfeição espiritual.

Em Drummond, tendo surgido pela primeira vez no poema "O Boi", de José (ANDRADE, 1967, p. 122), o motivo retorna ainda em A rosa do povo, no poema "Episódio" (ANDRADE, 1967, p. 156-157) e em Claro enigma, no poema "Um boi vê os homens" (ANDRADE, 1967, p. 238). Na tríade memorialista, contudo, a figura parece ganhar uma forma de tratamento especial.

Em "Destruição", a morte já é pré-anunciada no próprio título: mais do que a forma de um tratamento solene, o acontecimento é explorado em sua potência destrutiva ${ }^{12}$, produzindo ressonância para além do ambiente animal:

No pasto mal batido morre o zebu picado de cobra morre o zebu vindo de Cantagalo

disso levei um coice e não tive nada... Tudo é admirável. Tudo é gostoso e bom" (ANDRADE; ANDRADE, 2002, p. 237-239). Um mês depois, no entanto, volta a lamentar: "Estou de novo neste fim de mundo, precisando ser consolado" (ANDRADE; ANDRADE, 2002, p. 244). Drummond ainda permaneceu em Itabira pouco tempo, como professor no Ginásio Sul-Americano, cargo obtido por intermédio do irmão Altivo. Por esses mesmos dias, por cinquenta contos de réis, o mesmo Altivo comprou do irmão, então definitivamente rompido com a sua curta experiência de proprietário rural, a sua parte na Fazenda do Pontal. Em fins de 1926, o poeta começou a trabalhar no Diário de Minas, quando então se mudou para Belo Horizonte, mostrando-se aliviado: "Sabe que me mudei de Itabira? Mudei. Não pretendo mais voltar pra lá” (ANDRADE; ANDRADE, 2002, p. 252-255). No ano seguinte, Drummond e Dolores perdem o primeiro filho, Carlos Flávio.

12 A forma de tratamento metafórica do boi morto enquanto carcaça, destroço, ligada ao sentimento de angústia perante a iminência da destruição pode ser observada no poema Une charogne, de Baudelaire, em que a amada é colocada diante do espetáculo horrendo da carcaça em decomposição, e advertida de seu destino semelhante: "Et pourtant vous serez semblable à cette ordure, / A cette borrible infection, / Étoile de mes yeux, soleil de ma nature,/ Vous, mon ange et ma passion." (BAUDELAIRE, 1968, p. 29). 
com que rebuliço de estrada de ferro

com que sacrifício de estrada de barro

com que orgulho de dono da terra

morre o boi indiano

com que silêncio de urubus

na tronqueira perto.

Ao longo dos nove versos que compõem o poema, a morte do boi de Cantagalo se repete diretamente em três; em outros quatro, o lamento indignado em torno do fato também se repete, indicando, malfadado o rebuliço da chegada, o sacrifício do trajeto, o orgulho do proprietário, o silêncio dos que assistem o seu fim. Mais do que a morte que aconteceu, a repetição da tônica lamentosa - "morre", diferente do que aconteceria caso a repetição do verbo "morrer" tivesse sido utilizada em sua forma pretérita - parece evidenciar a perenidade de um acontecimento que, infiltrado nas rachaduras do presente imediato daquele que rememora, ecoa ainda, insistente, na redundância vã da impossibilidade de se aceitar aquilo que não se pode entender.

No livro seguinte, a morte do boi, agora nomeado, retorna em "O belo boi de Cantagalo":

Por trás da bossa do cupim

a cobra espreita

o belo boi de Cantagalo

trazido com que sacrifício

de longas léguas a pé e lama

para inaugurar novo rebanho

dos sonhos zebus do Coronel

Por trás da bossa do cupim

a cobra, cipó inerte,

medita cálculo e estratégia,

e o belo boi de Cantagalo

mal sente, sob o céu de Minas,

chegar o segundo-relâmpago

em que o cipó se alteia, se arremessa

e fere e se enrodilha e aperta

e aperta mais, aperta sempre

e mata.

Já não cobrirá as doces vacas 
ao seu destino reservadas

o belo boi de Cantagalo

e queda ali,

monumento desmantelado.

A bossa jaz ao lado da outra bossa, no imóvel sol do meio-dia.

Além do crescente desespero, intensificado pelos recursos de repetição e polissíndeto, e da composição da cena do ataque que se dá sob "o segundo relâmpago" que o céu de Minas anuncia, um dado novo, constante nos dois últimos versos da primeira estrofe, ajuda a imprimir dramaticidade ao acontecimento: o boi de Cantagalo, macho em sua sexualidade animal, tinha a missão de inaugurar novo rebanho. Quando sucumbe à queda $\mathrm{e}$ vai, por fim, ao chão, "monumento desmantelado", morre com ele a promessa de vida futura, sugestionada pela sonoridade do crescente tônico do excesso e da desmesura ("monumento"), e que se converte na descompensada sonoridade aberta da matéria "desmantelada”, estatelada ao chão. O boi imenso agora é carcaça imóvel.

De certa forma, em seu aspecto desmantelado, podemos considerar a imagem do boi como equiparada à do próprio sujeito, sob a figura de uma forma pronta à degradação. Ao retornar a um poema, a experiência-limite, sugerida pelo confronto com o fim último parece encarnar ainda um horror primitivo diante da morte, em que o boi é agora uma espécie de duplo do próprio Eu minado pela destruição.

O momento da visão do ser a caminho da destruição implica, de alguma forma, uma ética fundada na exigência de uma atitude de familiarização com a morte, como uma forma de aprender a morrer. O espaço do poema é também o lugar dessa aprendizagem, já que falar poeticamente e desaparecer pertencem à profundidade de um mesmo movimento: aquele que canta deve se entregar por inteiro ao jogo e, no fim, perecer, porquanto ele só fala quando a aproximação antecipada da morte, a separação adiantada, o adeus feito de antemão, apagam nele a falsa certeza do ser, dissipam as seguranças protetoras, entregam-no a uma insegurança ilimitada (BLANCHOT, 2011, p. 170). 
A relação maior do poeta (a arte) com a morte é este abandonar-se ao "velho monstro da impotência" (BLANCHOT, 2011, p. 113) ${ }^{13}$ e, neste ato, fazer da impotência um poder: o de converter o visível no invisível, que é a própria tarefa de morrer. Salva-se, assim, o perecível, mas para torná-lo invisível, para que ressuscite em sua invisibilidade, promessa de sobrevivência.

\section{"Não amadureci ainda bastante / para aceitar a morte das coisas"14}

Nos versos finais de "O belo boi de Cantagalo", o termo "bossa", presente logo no início - primeiro verso da segunda estrofe - é retomado no desfecho para contrastar com a figura já morta do boi:

e queda ali,

A bossa jaz ao lado da outra bossa, no imóvel sol do meio-dia.

Fechando a cena, desponta a imagem enigmática do sol do meio-dia. Para além de todo o misticismo que comumente se atribui ao Sol ${ }^{15}$, o que mais nos chama a atenção na escolha do desfecho do poema é o ambíguo "meio-dia”. Assim como nas pinturas de Giorgio de Chirico, nas quais, não raro, o elemento humano tornado manequim humanoide se vê banhando na contraluz indecisa do meio-dia (ou da meia-noite?), a luz do meio-dia (préanúncio do fim ou de um novo início?), pode ser entendida aqui enquanto derradeira e ambígua linha limítrofe que divide noite e dia.

Como numa visão ontológica, que buscasse a fonte do ser e do não ser, o movimento implícito de vida e decomposição tende para o resto das coisas, para o que já não é,

\footnotetext{
13 Mallarmé em carta a Cazalis, 14 de novembro de 1869.

14 "O fim das coisas", Boitempo III (ANDRADE, 1979, p. 141).

15 Muitos deuses, em diversas culturas, estão associados ao Sol, como por exemplo Surya, o Deus do Sol védico que simboliza o renascimento e a imortalidade; Khepri, Deus egípcio do Sol do Amanhecer que simbolizava a ressurreição. O fato que pode passar despercebido é que Sol e Lua, tomados em sua dualidade, são comumente tratados como um único símbolo, creditado a Zoroastro, considerado um dos principais mestres dos Antigos Mistérios, chamado por muitos de Pai do dualismo.
} 
o poeta une, no mesmo verso, boi e cupim, cupim devorando madeira, terra que em breve devorará o boi. O monumento de outrora se desmantela, rumo ao destino último e comum do existente, redemoinho onde o fim é também começo: o que gera e faz nascer, é também origem do impulso para a morte.

\section{THE OX'S DEATH: TRACES OF THE TRAGIC IN BOITEMPO}

ABSTRACT: This paper proposes the reading of two poems by Carlos Drummond de Andrade "Destruição" and "O belo boi de Cantagalo" which composes the trilogy called Boitempo - as from the image of ox and your relation with the death not just as direct reference to the Andrade's clan but also and mainly in your potentially tragic aspect. In other words, the ox in these poems can be read as mark or sign of perenniality that travels through of the time to reassert your perennity by the transformation.

KEYWORDS: Carlos Drummond de Andrade; Memory; Poetry.

\section{REFERÊNCIAS}

ANDRADE, Carlos Drummond de. Obra completa. Rio de Janeiro: José Aguilar Editora, 1967.

- Boitempo \& A falta que ama. Rio de Janeiro: Sabiá, 1968.

. Menino Antigo: Boitempo II. Rio de Janeiro, Livraria José Olympio Editora; Brasília, Instituto Nacional do Livro, 1973.

. Esquecer para lembrar: Boitempo III. Rio de Janeiro: J. Olympio, 1979.

ANDRADE, Carlos Drummond de.; ANDRADE, Mário de. Carlos \& Mário: Correspondência de Carlos Drummond de Andrade e Mário de Andrade. Org. Lélia Coelho Frota. Rio de Janeiro: Bem-Te-Vi, 2002.

ANDRADE, M. de. "Do trágico”, In: O empalhador de passarinho. São Paulo; Brasília: Martins Fontes; INL, 1972, p. 111.

BAUDELAIRE, C. Oeuvres complètes. Ed. Le Dantec, rev., aum. e apresentada por Claudee Pichois. Bibliothèque de la Pléiade. Paris: Gallimard, 1968.

BENJAMIN, Walter. Obras escolhidas 1: magia e técnica, arte e política. Trad. Sérgio Paulo Rouanet; prefácio Jeanne Marie Gagnebin. 8a ed. Revista. São Paulo: Brasiliense, 2012.

BLANCHOT, Maurice. O espaço literário. Trad. Álvaro Cabral. Rio de Janeiro: Rocco, 2011. BOSI, Alfredo. “A Máquina do Mundo entre o Símbolo e a Alegoria”, In: Céu, Inferno. 1988. 
CAMILO, Vagner. Drummond: Da rosa do povo à Rosa das Trevas. São Paulo: Ateliê Editorial, 2001.

CANÇADO, José. Maria. Os Sapatos de Orfeu: biografia de Carlos Drummond de Andrade. São Paulo: Globo, 2012.

CANDIDO, Antonio. "Inquietudes na poesia de Drummond”. In: Vários escritos. São Paulo: Duas Cidades, 1970.

"A autobiografia poética e ficcional na literatura de Minas". In: FRANCO, A.A. de. $\mathrm{M}$ et al. IV Seminário de Estudos Mineiros. Belo Horizonte: Imprensa Universitária da UFMG, 1977.

Paulo: Ed. Ática, 1989.

CORREIA, Marlene de Castro "A inteligência trágica do universo", In: A magia lúcida. Rio de Janeiro: Jorge Zahar Ed., 2002, p. 86.

MERQUIOR, José Guilherme. Verso Universo em Drummond. Trad. Marly de Oliveira, 3. ed. São Paulo: É Realizações, 2012.

TEIXEIRA, Jerônimo. Drummond cordial. São Paulo: Nankin Editorial, 2005.

Recebido em: 03/06/2018.

Aprovado em: 02/08/2018. 